\title{
SANG NOTO: \\ PENCIPTAAN KARYA INTERMEDIA DENGAN SUMBER IDE PUISI-PUISI NOTO SOEROTO DALAM KUMPULAN PUISI WAYANG-LIEDEREN
}

\author{
Joko Aswoyo ${ }^{1)}$, Albertus Rusputranto P.A. ${ }^{2)}$ \\ ${ }^{1}$ Fakultas Seni Pertunjukan Institut Seni Indonesia (ISI) Surakarta \\ joko.aswoyo@gmail.com \\ ${ }^{2}$ Fakultas Seni Rupa, Institut Seni Indonesia (ISI) Surakarta \\ titusclurut@yahoo.co.uk
}

\begin{abstract}
ABSTRAK
Penelitian ini bertujuan untuk menciptakan sebuah pertunjukan interdisiplin seni dengan judul "Sang Noto". Proses penciptaan Sang Noto menggunakan metode penciptaan seni intermedia. Dalam karya ini media-media yang berbeda didialogkan dan dikolaborasikan sehingga menghasilkan satu bangunan karya seni. "Sang Noto" bertolak dari puisi-puisi karya Noto Soeroto, Wayang-liederen, yang kemudian ditafsir dan diekspresikan dalam bentuk karya seni intermedia.
\end{abstract}

Kata kunci: Sang Noto, seni intermedia, wayang-liederan

\begin{abstract}
This study aims to create an interdisciplinary art performance entitled "Sang Noto." The process of creating "Sang Noto" uses the intermedia art production method. In this work, different media are mixed and collaborated to produce a construction of art. "Sang Noto" departs from Noto Soeroto's poetry, Wayang-liederen, which is then interpreted and expressed in the form of intermedia artworks.
\end{abstract}

Keywords: Sang Noto, intermedia art, Wayang-liederen

\section{PENDAHULUAN}

Perjumpaan berbagai medium, berbagai disiplin ilmu dan ekspresi artistik/estetika tidak terelakkan dalam penciptaan seni pertunjukan. Fenomena ini tidak terjadi hanya dalam wacana seni kontemporer saja. Karya-karya pertunjukan dalam ranah tradisi (Jawa) berhubungan erat dengan praktik-praktik intermedium dan alih wahana. Banyak karya pertunjukan tari tradisi Jawa, utamanya yang muncul dari dalam tembok karaton, lahir dari gendhing dan atau karya-karya sastra Jawa. Sumber-sumber artistik yang sudah berbentuk karya-karya artistik tersebut dialihwahanakan dan dikawinkan (dikolaborasikan) menjadi sebuah karya seni baru yang lebih kaya.

Sumber-sumber yang memberikan sumbangan, baik konsep maupun ekspresi artistik, pada karya seni yang baru tersebut tidak kemudian dihilangkan jejak-jejaknya. Semuanya hadir dan saling menguati meskipun tentu semuanya harus patuh dalam kerangka dasar penciptaannya. Karya sastra dan gendhing (sastra gendhing) yang auditif, misalnya, akhirnya harus hadir juga secara visual dalam bentuk gerak-gerak artistik karena kerangka penciptaan karya yang ditetapkan adalah seni tari.

Kuatnya modernisme mempengaruhi konsepsi-konsepsi seni dalam dunia kesenian kita, membuat seolah-olah ada sekat yang begitu masif membatasi dan membagi ekspresi-ekspresi seni dalam kamar-kamarnya sendiri. Semisal, dalam wacana pemikiran ini seolah-olah ekspresi seni rupa steril dari pengaruh seni sastra dan bentuk-bentuk seni yang lain. Demikian juga, ekspresi seni tari steril dari 
pengaruh seni rupa dan bentuk-bentuk seni yang lain, dan sebagainya.

Khasanah tradisi seni masyarakat Jawa sebenarnya tidak mengenal penyekatan-penyekatan masif serupa itu. Tradisionalisme, yang dirumuskan oleh wacana pemikiran modern, yang mengkotak-kotak dan membaginya hingga menciptakan kasta-kasta; seolah-olah ada karya yang lebih luhur dibanding karya yang lain. Fenomena inilah satu dari dua persoalan yang menggelisahkan sehingga merasa perlu mencoba melihat kembali kekuatan tradisi penciptaan seni dalam kebudayaan Jawa, yang multidimensional, yang intermedium, sebagai semangat dasar penciptaan karya seni tari kali ini.

Penelitian artistik ini mencoba menciptakan sebuah karya intermedia yang tidak berbeda dengan para kreator kesenian tradisi Jawa pendahulu yang bertolak dari karya sastra. Karya intermedia ini membuka kemungkinan kehadiran ekspresi-ekspresi seni lain (seni musik, seni rupa, seni media rekam dan lainlain) dalam keseluruhan bangunan artistiknya.

Untuk membingkai karya sastra yang menggugah penciptaan karya intermedia ini adalah puisi-puisi Noto Soeroto yang ditulisnya dalam bahasa Belanda dan dibukukan dengan judul Wayang-liederen (Dendang Wayang). Buku kumpulan puisi itu diterbitkan tahun 1931 ketika ia masih tinggal di Belanda. Bertolak dari pemahaman atas puisi dalam buku Wayang-liederen atau Dendang Wayang (Kerdjik, 2002: 203-256). maka perlu dipaparkan konsep penciptaan dan proses penciptaan karya intermedia dalam penelitian artistik yang berjudul "Sang Noto: Penciptaan Karya Intermedia dengan Sumber Ide Puisi-puisi Noto Soeroto dalam Kumpulan Puisi Wayang-liederen".

\section{KAJIAN LITERATUR}

Gagasan tentang penelitian artistik yang berjudul "Sang Noto: Penciptaan Karya Intermedia dengan Sumber Ide Puisi-Puisi Noto Soeroto Dalam Kumpulan Puisi Wayang-Liederen" diilhami dari karya Joko Aswoyo yang berjudul Noto (2018).

Noto merupakan karya kolaborasi an- tara beberapa seniman dengan latar belakang kesenian yang berbeda-beda: tari, musik, dan seni rupa. Karya pertunjukan ini mencoba mempertemukan konsep artistik Piet Mondrian, perupa Belanda yang banyak menginspirasi pertumbuhan seni rupa modern di Eropa dan ide-ide serta kegelisahan Noto Soeroto, seorang jurnalis, intelekual, nasionalis yang juga sastrawan, yang berasal dari dalam pura Pakualaman (Kerajaan Vassal, Dinasti Mataram Islam), Yogyakarta. Keduanya hidup pada zaman yang sama dan sama-sama penganut theosofi. Sayangnya selama hidup mereka belum pernah bertemu.

Keduanya mempunyai kcenderungan yang hampir sama, setidak-tidaknya sama-sama penganut theosofi, sama-sama hidup dalam satu zaman, pernah sama-sama hidup di negeri Belanda dan sama-sama melakukan kerja-kerja artistik.

Proses kerja kolaborasi penciptaan Noto ini, menemukan bentuk karya pertunjukan dan belum pernah dilakukan oleh seniman-seniman lain di tanah air: mempertemukan Piet Mondrian dan Noto Soeroto dalam satu panggung. Piet Mondrian diwakili oleh tata artistik dan properti sedangkan Noto Soeroto sebagai tokoh yang ada dalam ruang pertunjukan.

Di atas panggung pertunjukan ada tiga orang penari dan seorang pemusik. Ketiganya merepresentasikan hal ikhwal Noto Soeroto sekaligus sebagai bagian dari elemen-elemen visual (artistik visual) dalam ruang pentas. Demikian juga peran seorang pemusik yang berada di atas pentas. la hadir bukan sebatas pemusik tetapi juga sebagai bagian dari elemen visual dari pertunjukan. Hans Breder, "Intermedia: Enacting the Liminal", Performing Arts Journal, May - Sep., 1995, Vol. 17, No. 2/3, The Arts and the University (May - Sep., 1995), pp. 112-120 merupakan pengalaman penulis ketika proses mengerjakan karya intermedia di Amerika. Intermedia adalah karya kolaboratif, berlandaskan konseptual, performatif, ritualistik, spesifik lokasi. Intermedia berada di ruang liminal saat interaksi dua atau lebih media menyebarkan ide-ide baru, bentuk-bentuk baru, cara-cara baru untuk 
melihat dan menjadi sesuatu.

Selanjutnya yang menarik dari catatan pengalaman pribadi ini bahwa setiap kehadiran karya intermedia membutuhkan pemahaman atas beragam perspektif yang berdasarkan pada kekuatan dan proses penciptaan setiap bidang seni.

Kemudian Kate Sicchio mengadakan eksperimen penciptaan intermedia pada para anak didiknya. Point penting dari artikel yang berjudul Perceptions of Collaborative Learning in Intermedia and Performance Arts ini bahwa setiap proses penciptaan karya intermedia membutuhkan seperangkat pengetahuan yang penting sebagai kerangka proses kerja bersama-sama. Saling nge-mong merupakan modal sosial awal dalam sebuah karya intermedia. Seniman-seniman yang memiliki seperangkat nilai sosial dan budaya yang sadarnmenghargai betapa penting kerjasama sebagai modal awal yang dapat merealisasi sebuah karya intermedia.

\section{METODE PENELITIAN}

Rancangan kegiatan dalam mengawali kerja penciptaan karya intermedia Sang Noto ini, berangkat dari beberapa media: ruang, benda atau elemen visual, cahaya, dan penari, suara vokal, dan pemusik.

Dengan segala kelebihan dan kekurangan, beberapa media ini mempunyai kekuatan untuk hadir menjadi karya mandiri. Namun dalam karya intermedia ini media-media tersebut disatupadukan menjadi satu kesatuan, keselarasan, dan masing-masing mempunyai otoritas untuk hadir dalam satuan ruang dan waktu. Dengan dipandu dan dipicu oleh karya puisi maka dalam proses interaksi antar media yang secara sensitif terjalin terus-menerus saling mengisi, membentuk, hingga menghasilkan sebuah entitas baru.

Uraian di atas merupakan kerja inter disiplin. Masing-masing bidang seni di atas berpartisipasi membangun kesatuan pameran pertunjukan. Dengan demikian intermedia dalam karya Sang Noto sebagai bentuk kinerja interdisipliner. “... intermedia as a concept is interdisciplinary and to create such a performance requires collaborative working" (Sicchio, 2013: 15).

Penelitian ini intermedia sebagai sebuah konsep bersifat interdisipliner dan untuk mewujudkan pertunjukan tersebut diperlukan kerja kolaboratif. Semua disiplin ilmu seni tidak hanya harus menyumbangkan materi dari sudut pandang mereka, tetapi juga menyadari bagaimana hal ini disampaikan dalam keseluruhan pertunjukan dan hubungan yang dibuatnya dengan disiplin lain dalam karya tersebut.

Penelitian penciptaan lintas disiplin ini dengan kerangka awal sebagai titik berproses bersama yang berupa puisi Ciptaan Noto Soeroto yang berjudul Lakon dan Sang Resi dan Sang Raja.

...a theme might serve as the starting point for an interdisciplinary collaboration between artists from various disciplines / dance, music, theatre (Sicchio, 2013: 13).

Dengan berpijak dari tema tersebut kemudian karya intermedia itu memerlukan plotplot adegan, namun dalam proses eksplorasi kadang ada sesuatu yang tidak dapat diprediksi sebelumnya (meskipun telah dipandu dengan rancangan pola-pola tertentu yang dibangun oleh hubungan antar keseluruhan media itu.

Ruang sebagaimana dalam konsep pertunjukan pada umumnya, hadir sebagai tempat berkomunikasi. Ruang yang sudah ditetapkan diungkapkan dan dihidupkan. la dieksplorasi dan digarap agar memperkuat pertunjukan itu sendiri (Dipayana: 132).

Pilihan atas ruang dari karya intermedia Sang Noto ini adalah sebuah ruang prosenium sebagai medan ekspresi. Ruang pentas berukuran lebar 25 meter, kedalaman 12 meter dan ketinggian sekitar 7 meter. Dalam karya intermedia ruang pentas prosenium diibaratkan sebagai sebuah kanvas tiga dimensional. Pilihan atas ruang tersebut untuk memperoleh jarak antara lukisan dan penikmatnya.

Benda-benda visual sebagai unsur penting dari karya intermedia ini. Benda-benda tersebut ditata sedemikian rupa, tidak statis; bergerak, berubah, membentuk ruang-ruang baru. Dinamika ruang itu dicipta oleh para penari dengan 
menjadikan benda visual itu sebagai properti dan atau kemudian dihadirkan menjadi benda visual lain.

Kanvas tiga dimensional ini berada dalam alur waktu, ruang bagi hadirnya ekspresi artistik yang dibangun oleh benda-benda, cahaya, dan para aktor. Pertujukan intermedia ini ibarat rangkaian lukisan yang hadir tiada henti di hadapan penikmatnya. Fokus lukisan ini pun setema tetapi berlainan fokus antara satu dengan yang lain.

Lukisan tiga dimensional ini pengkarya mempertimbangan keterhubungan antara lukisan satu dengan yang lain. Seluruh lukisan adalah tema yang terbungkus dalam rangkaian cerita panjang dalam bingkai waktu yang berlainan.

Lukisan tiga dimensional ini dihadirkan oleh kain berwarna putih dan beberapa kain berwarna lain dalam momen atau adegan tertentu.

Kain-kain itu ada yang bergantung dan tertambat dari sudut ruang menjulur ke sudut ruang lain. Dalam ruang itu, bergantung peralatan lampu dengan beragam jenis dan karakter cahaya. Cahaya merupakan elemen penting dalam menghadirkan ekspresi artistik dalam ruang pertunjukan ini. Pilihan atas jenis dan karakter lampu, distribusi, intensitas, dan warna akan membangun lukisan yang selalu bergerak dan berubah di setiap waktu. Sifat-sifat cahaya di atas untuk memperjelas keberadaan segala sesuatu di atas pentas, membangun fokusfokus pilihan, dan atau membangun suasana (Aswoyo, 2006: 64-78). "stage lighting must perform several basic function: visibility, selective focus, modelling, mood (Gillete, 1978: 4-7). Tata cahaya untuk menjelaskan keberadaan, memperlihatkan setting, menciptakan suasana dan memperkuat tema. The function stage lighting: Designing With Light fisibility, establishing the mood, reinforcing the theme (Parker \& Smith, 1962: 376-378). Demikian juga dalam konteks karya intermedia: fungsi tata cahaya menggabungkan beberapa elemen komposisional.

Keberadaan aktor, baik penari dan pemusik, merupakan unsur lain sebagai pembangun ungkapan-ungkapan artistik dalam kanvas ruang pertunjukan. Suara petikan, atau suara tiupan instrumen musik, dan vokal adalah bahan atau unsur pembentuk dari karya intermedia ini.

Pada dasarnya keseluruhan unsur pertunjukan ini adalah sejumlah lukisan yang selalu berada dalam ruang dan waktu yang berbeda-beda. Lukisan-lukisan ini, dengan objek yang berlainan dan selalu berubah, digarap dinamisasi ruang pentasnya sehingga menjadikan lukisan lebih hidup. Penari, pemusik dan objek visual yang ada di dalamnya menjadi roh pada setiap adegan dan dalam ruang pentas atau kanvas tersebut. Para penari atau pemusik kadang berada di sudut ruang pentas namun kadang berada di tempat lain. Mereka membentuk visual dengan benda-benda, warna-warna, dan terpaan cahaya.

\section{HASIL DAN PEMBAHASAN}

Pementasan "Sang Noto" diawali dengan penayangan video dokumentasi Noto Soeroto yang tengah menyampaikan pidato perpisahan dalam bahasa Belanda (https:// zoeken.beeldengeluid.nl/program/urn:vme:default:program:2101608140120043531/asset/ urn:vme:default:asset:2101610180609913321/ segment/urn:vme:default:logtrackitem:2101703 040123342724 ?ac=dgtl\&q=noto+soeroto). Dalam pidatonya, Noto Soeroto menegaskan (lagi) gagasan nasionalismenya. Video ditembakkan di atas layar putih, yang dibentang menjulang di atas panggung. Adegan pertama ini dimulai setelah sebelumnya dramaturgi pementasan (Albertus Rusputranto P.A.) menyampaikan pengantar, menghantarkan dimulainya pementasan.

Pada film dokumenter tersebut tersirat esensi dari keseluruhan pertunjukan intermedia: Kegelisahan dan optimisme yang bergulat dalam diri Noto Suroto. Hal ini juga disampaikan oleh Jet Smeet, bahwa dalam film dokumenter tersebut Noto Soeroto sadar ada orang di sekitarnya yang menganggapnya gagal menumbuhkan pemulihan hubungan serta saling pengertian antara orang Belanda dan Indonesia. Noto Soeroto, dalam film dokumenter tersebut, mengatakan akan pulang tanpa kepahitan. Dan waktu saja yang akan membuktikan nilai dari visi-visinya (Jet Smeet). Adegan ini sebagai awalan; sebuah lukisan tiga dimesi dengan cahaya biru di samping kanan 
dan kiri (berbentuk empat persegi panjang untuk membangun kedalaman dari ruang pentas) dan layar putih dengan posisi di tengah (berada sedikit di depan kedua layar dengan warna biru tersebut). Hal ini untuk membangun kesan focus of interest dari adegan yang dimainkan. Di samping itu keberadaan warna biru (pada screen kanan dan kiri) sebagai upaya untuk membangun kontras dengan film dokumenter hitam putih (agar film lebih menonjol).

Setelah film dokumentar selesai diputar, panggung perlahan-lahan gelap. Lampu panggung fit in: tampak siluet penari perempuan (Sekar Tri Kusuma) yang bergerak di balik sekat putih. Adegan ini didominasi warna cahaya dengan pilihan jenis lampu Ellipsoidal Reflector Spotlight, berkarakter tajam tanpa warna (NC) No Colour. Hitam-putih sebagai lukisan berikutnya.

Terdengar lantunan puisi dengan suara yang saling menumpuk. Puisi "Lakon", karya Noto Soeroto (Kerdjik: 2002, 211-212), dibaca oleh Ista Bagus Putranto ${ }^{1}$ (suara laki-laki) dan Kalis (suara perempuan). Menutup adegan awal pementasan, penari bergerak menerjang batas, mengoyak sekat.

Pada adegan ke dua, puisi "Lakon" dilantunkan lagi. Kali ini dalam gubahan lagu. Lagu (dan musik) yang digubah oleh Gondrong Gunarto dari puisi "Lakon" ini dinyanyikan oleh Eta Novitasari dengan iringan suara petikan kecapi (Gondrong Gunarto) dan alunan seruling (Misbach Daeng Bilok)2. Musikalisasi puisi ini berlangsung sepanjang adegan dua. Lampu padam di akhir adegan.

Suara pada adegan kedua ini lebih menojol dari yang lain. Visual dan cahaya sebatas sebagai penjelas keberadaan benda dan aktor yang ada di ruang itu. Semua tertuju pada vocal, bunyi petikan kecapi dan tiupan

\section{Ista Bagus Putranto merekam} suara di Belanda lalu hasilnya dikirim, via voicemail, kepada Joko Aswoyo di Indonesia.

\section{Penata suara dan operator} sound system pementasan "Sang Noto": Adi Wasono dan Budi. seruling Jepang. (membayang di kain yang terpasang menjulang) mengawali adegan tiga. Beberapa saat kemudian penari tersebut, Luluk Ari Prasetyo, bergerak ke tengah panggung. Luluk menari di antara larik-larik cahaya merah dan biru sambil memainkan kain yang tergeletak membentang di atas panggung ${ }^{3}$. Keseluruhan gerak tari Luluk menyimbolkan proses hidup Noto Soeroto, dari sejak berada di negeri Belanda hingga kepulangannya di tanah Jawa; menyimbolkan berbagai tempaan dan deraan yang diterima Noto Soeroto sepanjang hidupnya memperjuangkan "kebenaran" yang diyakini.

Luluk menghadirkan beragam bentuk visual dari kain berwarna. la kibaskan kain-kain itu ke berbagai arah sebagai upaya untuk mendinamisir kanvas ruang pertunjukan.

Adegan empat menghadirkan dua orang penari senior, laki-laki dan perempuan. Penari laki-laki (Daryono) menari dan melantunkan tembang, sementara penari perempuan (Rusini) menari dan melantunkan doa (mantera). Adegan empat adalah adegan terakhir. Daryono dan Rusini dalam adegan ini memainkan gerak-gerak dramatik kontemplatif.

Mengakhiri adegan empat, yang artinya juga menjadi akhir dari seluruh adegan pertunjukan "Sang Noto", Jet Smeet mengalunkan puisi karya Noto Soeroto. Jet Smeet membaca "Sang Raja dan Sang Resi", dalam versi aslinya, dalam bahasa Belanda ${ }^{4}$. Tidak sampai seluruh puisi selesai dibacakan lampu perlahan-lahan black-out; pertunjukan selesai.

Visualisasi adegan terakhir ini dimaksudkan, oleh Joko Aswoyo, sebagai gambaran bangunan karakter Noto Soeroto, yang terbentuk dari berbagai persinggungan budaya, persinggungan pemikiran, pengaruh, konflik, kepentingan, idealisme, tradisi dan sebagainya;

3 Penata artistik pementasan "Sang Noto": Mohammad Nur Hadi dan Muhammad Arif Wijayanto. Operator layar pementasan "Sang Noto": Warginawan dan Saban.

$4 \quad$ Jet Smeet merekam suara di Belanda lalu hasilnya dikirim, via voicemail, kepada Joko Aswoyo di Indonesia. 
Noto Soeroto sebagai bagian dari masyarakat dunia sekaligus Jawa yang berusaha mendialogkan modernisme Barat dengan naluri-naluri tradisinya, yang mempertemukan ide asosiasi Tagore, cinta kasih Gandhi, nasionalisme, sastra Belanda dan wayang, yang hidup di antara rasionalitas Barat dan rajutan mantera-mantera ibunya.

Noto Soeroto dalam keseluruhan adegan pementasan "Sang Noto" direfleksikan sebagai pribadi yang telah "menemukan dirinya". Dan Wayang-liederen, dalam "Sang Noto", adalah satu di antara banyak cara nantinya Noto Soeroto bisa "dimainkan kembali", untuk sekali lagi bersuara dan berjuang mewujudkan kemanusiaan manusia-manusia Indonesia yang seutuhnya merdeka.

\section{KESIMPULAN}

Penciptaan karya intermedia Sang Noto ini, berangkat dari beberapa media: ruang, benda atau elemen visual, cahaya, dan penari, suara vokal, dan pemusik. Karya intermedia ini menjadi satu kesatuan, keselarasan, dan masing-masing mempunyai otoritas untuk hadir dalam ruang dan waktu tertentu. Proses interaksi antar media yang secara sensitif terjalin terus-menerus saling mengisi membentuk hingga menghasilkan sebuah entitas baru berupa komposisi-komposisi yang terbangun dan menjadi bagian dari adegan-adegan.

Karya intermedia "Sang Noto" adalah salah satu bentuk dari rangkaian lukisan yang bercerita. Cerita yang tak kunjung usai dengan pokok-pokok pikiran yang berbeda-beda di setiap bingkainya.

Noto Soeroto dalam keseluruhan adegan pementasan "Sang Noto" direfleksikan sebagai pribadi yang telah "menemukan dirinya". Dan Wayang-liederen, dalam "Sang Noto", adalah satu di antara banyak cara nantinya Noto Soeroto bisa "dimainkan kembali", untuk sekali lagi bersuara dan berjuang mewujudkan kemanusiaan manusia-manusia Indonesia yang seutuhnya merdeka.

\section{DAFTAR PUSTAKA}

Aswoyo, Joko. 2006. Di Balik Gelap Terang Cahaya. Surakarta: ISI Press.

Dipayana, Ags. Arya (ed). t.th. Warisan Roedjito Sang Maestro Penata Panggung Perihal Teater dan Sejumlah Aspeknya. Jakarta; Dewan Kesenian Jakarta,

Gillete, J. Michael, 1978. Designing With Light,California: Mayfield Publishing Company.

Hans Breder, "Intermedia: Enacting the Liminal" , Performing Arts Journal , May - Sep., 1995, Vol. 17, No. 2/3, The Arts and the University (May - Sep., 1995), pp. 112-120

https://zoeken.beeldengeluid.nl/program/urn:vme:default:program:2101608140120043531/ asset/urn:vme:default:as set:2101610180609913321/segment/ urn:vme:default:logtrackitem:21017030 40123342724? ac=dgt \& $q=$ noto+soeroto

Ista Bagus Putranto merekam suara di Belanda lalu hasilnya dikirim, via voicemail, kepada Joko Aswoyo di Indonesia.

Jet Smeet, Seni Bisa Menafsir Kehidupan, sebuah tanggapan/ komentar atas film dokumentasi tentang Noto Suroto.

Kerdjik, Rosa M.T. Wayang- liederenn:Biografi Politik Budaya Noto Soeroto. Jakarta Selatan: Komunitas Bambu, Yayasan IKAPI dan Ford Foundation.

W. Parker, W. Oren, dan Harvey K Smith. 1963. Scene Design and Stage Lighting. Florida: Harcourt Brace Jovanovich Inc.

Sicchio, Kate, 2013. "Student Perceptions of Collaborative Learning in Intermedia and Performance Arts", Learning and Performance Quarterly, 1 (4) 